\title{
Additive Manufacturing: Is It a New Era for Furniture Production?*
}

\author{
Murat Aydin \\ The Department of Material and Material Processing, Sutculer Vocational School, Suleyman Demirel University, Isparta 32260, Turkey
}

\begin{abstract}
The purpose of this study is to make a review and or definition of AM (additive manufacturing), and an evaluation of its use in furniture production within a few projects to provide industry-specific awareness. AM can be considered as one of the latest innovative processes, as a state-of-the-art development, in manufacturing industries. AM is expressed as the future of the products and localization of the manufacturing processes in some studies. Innovation is a key factor both for firms and consumer products or service output. And, in today's competitive environment, it compels all the partners for R \& D activities to provide technological development. But, all the partners come to a parting of the ways of disruptive or sustainable innovation. It can be said that furniture manufacturing by AM method is relatively new. Non-industrial use of the AM in furniture production can be stated as one of the latest innovative development. Thereby, this study reviews how AM is used to produce furniture within applied projects, which materials and methods are used for production and suggests its future impact.
\end{abstract}

Key words: 3D Printing, additive manufacturing, furniture, furniture design, furniture production.

\section{Introduction}

Transformation of inputs such as raw material, semi-finished material, machinery, labor, management and investment to the physical products or service outputs through transformation processes is called production. Manufacturing is the production of goods for merchandise and crucial for economic advancement in today's competitive environment. And, it is changing profoundly with the technological developments. In conventional production, there is movement of material between stations and also materials rotate around their own axis because of cutting, drilling, assembly and so on transactions. This causes waste and leeway. But in AM (additive manufacturing), there is almost no wastage and leeway like in conventional systems due to decreased work stations. Because of this, goods can be practically

Corresponding author: Murat Aydin, Ph.D. candidate, research fields: furniture design and manufacturing. E-mail: murataydin@sdu.edu.tr.

*This study is a revised version of "Use of 3D printing in Furniture Production" which has been presented as oral presentation in "3rd Int. Symposium on Innovative Technologies in Engineering and Science" in Valencia between 3-5 June 2015 and published online. finished in a few stations; a computer for modeling and generating the production data, a 3D printer for manufacturing and finishing processes for surface quality. For example if the model is formed with interwoven parts, end products can be finished in a few hours, and finishing time takes a few days depending on surface quality expectations in AM [1]. According to Gibson et al [1], it takes weeks for the same material handling in conventional $\mathrm{CNC}$ machining. Because of this speed advantage, AM is commonly used for prototyping or fixture manufacturing. But according to Winnan [2], more than $20 \%$ of AM outputs are end products instead of prototype in 2011 and it is estimated that this ratio will rise to $50 \%$ in 2050 . According to the Berger [3] in 2012, market size of AM without discrimination of prototype or end goods including system, service and material was $€ 1.7 \mathrm{bn}$ and it's estimated that market size will be quadruple over the next 10 years. According to Wohlers Report 2013, it was $\$ 2.2 \mathrm{bn}$ in 2012 [4]. Cost of AM is still considerable higher than the conventional systems for mass production even though the market size grows. For instance, ABS (acrylonitrile butadiene styrene) 
material in mass production costs US $\$ 2$ a kilo while US\$80 a kilo in AM [5]. According to Berger [3], 60\% and later on $30 \%$ fall is expected about costs for the next five years.

AM may be the next step or future of modern manufacturing and this idea is becoming significant with this projection. According to Santos et al. [6], AM's main markets are aerospace, automotive and medical industries for rapid prototyping, rapid manufacturing, mass customization and mass production. These markets can be considered as high value adding products' market and products are relatively smaller than furniture. But, nowadays use of AM methods for furniture production is becoming widespread despite the fact that it is not easy to manufacture real furniture. Because, there are questions to be answered such as surface finishing and quality, mass production capability, furnishing, hardware installation, dimension, mechanic properties and etc. in furniture manufacturing. Also, craftsmanship is an important factor in furniture production and especially for the classic formed furniture because of the assembly works. Assembly work is an important and time consuming stage in furniture manufacturing. AM can also eliminate this stage due to its production method. Thereby, this study aims to investigate how AM is used to produce furniture within applied projects, which materials and methods used for productions. Also, creating awareness about furniture production by using AM is the minor aim of this study.

\section{Additive Manufacturing}

"The use of a computer-aided design-based automated manufacturing process to construct parts that is used directly as finished products or components" definition is used to describe AM by Majewski [7] while originally used to describe rapid manufacturing by Hopkinson et al. [8]. But according to Buswell et al. [9], rapid manufacturing, rapid prototyping, solid freeform fabrication, additive manufacturing technologies entitle the same family of processes. In this study, AM is preferred to express this technology. Nowadays, AM is getting more attention due to innovative developments despite the fact that its history goes back to early 1980s.

AM can use thermoplastic, ceramic, metal alloy, metal matrix composite, stainless steel, aluminum, thermoplastic ceramic or metal powder, paper, metal foil, plastic film, photopolymer materials to form the layers. According to Hopkinson et al. [8], layer forming materials divided into three classes: liquid, powder or solid materials by means of the material properties. SLM (selective laser melting), direct metal laser sintering, SLS (selective laser sintering), fused deposition modeling, laminated object manufacturing and stereolithography are the mainly used layer forming methods. All the methods use the same basic processing steps seen in Fig. 1.

CAD modeling is the first and one of the most important processes of the manufacturing because if the model is wrong, end products will be wrong too. This occurs because the end products are manufactured directly from CAD models. Data transformation of the
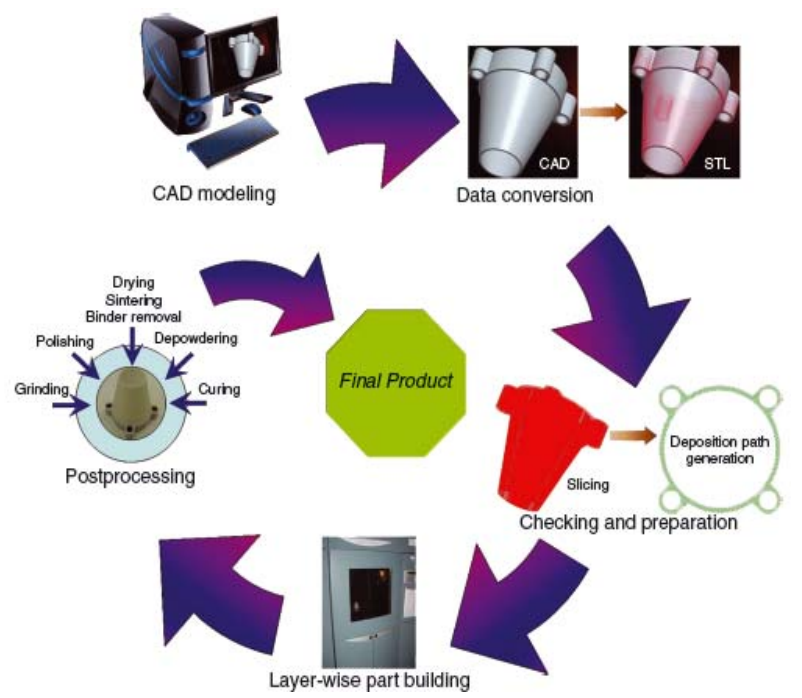

Fig. 1 Basic processing steps in AM [10].

CAD model (Regardless of 3D modeling software used) into the STL (standard tessellation language), OBJ (object file) or AMF (additive manufacturing file format) formats, slicing the model for laying down 
material in layers, control and preparation, manufacturing process, finishing works are the basic processing steps for all AM methods as seen in Fig. 1. Only layer-wise part building and post-processing works differ according to the manufacturing method.

FDM (fused deposition modeling), as seen in Fig. 2, uses solid materials like thermoplastic filament or metal wire to melt through nozzle while forming the layer by movement of nozzle according to additive deposition route generated by software after slicing the model. According to Dudek [11] PC (Polycarbonate), PLA (polylactic acid), PPSF (polyphenylsulfone) and mix of these types of materials are the common used materials after the ABS in FDM method. But According to Gibson et al. [1], this method has some problems such as processing speed, precision and material density. Also a support material is needed to sustain the melted material during the cooling. It means that it's difficult to form stalactite-like designs but according to Celik et al. [12], a secondary nozzle can be integrated for fulfilling this purpose.

$3 \mathrm{D}$ printers are integral part of the AM systems and vary in volume, resolution, printing speed and used material. Some of 3D printers' properties are seen in Table 1. These printers are especially designed for producing small object due to printing volume. But, some $3 \mathrm{D}$ printers, especially robotic armed as the one seen in Fig. 3, can overcome volume limitation and can print bigger parts.

Galatea is one of these 3D printers robotic arms which is designed and modified from an old assembly line robot of automotive industry to especially manufacture furniture [16]. According to Dehue [17], robotic arm 3D printers robotic arms are 40 times faster than conventional ones for furniture manufacturing.

But these types of printers are more expensive than others. And, according to Andres [4], prices of these printers vary between $£ 30,000$ and $£ 500,000$.

Resolution is one of the key factors because it defines the shape clarity and dimensional accuracy of product with the layer thickness. According to Dogan [19], accuracy directly affects the surface roughness. Resolution (dpi) and layer thickness $(\mu \mathrm{m})$ describe the surface quality as well. Layer thickness also depends on layer slicing parameters. Sliced layers of the model and scanning direction can be seen in Fig. 2b. Printer resolution has an important effect on surface aesthetic too and according to Gibson et al. [1], end products need post-processes due to lack of aesthetic and performance. Fig. 4 shows an evidence of these disadvantages. According to Lanzetta and Sachs [20] use of bimodal powders provides much improved surface finish. Surface modification is one of the primary concerns and studies are in progress.

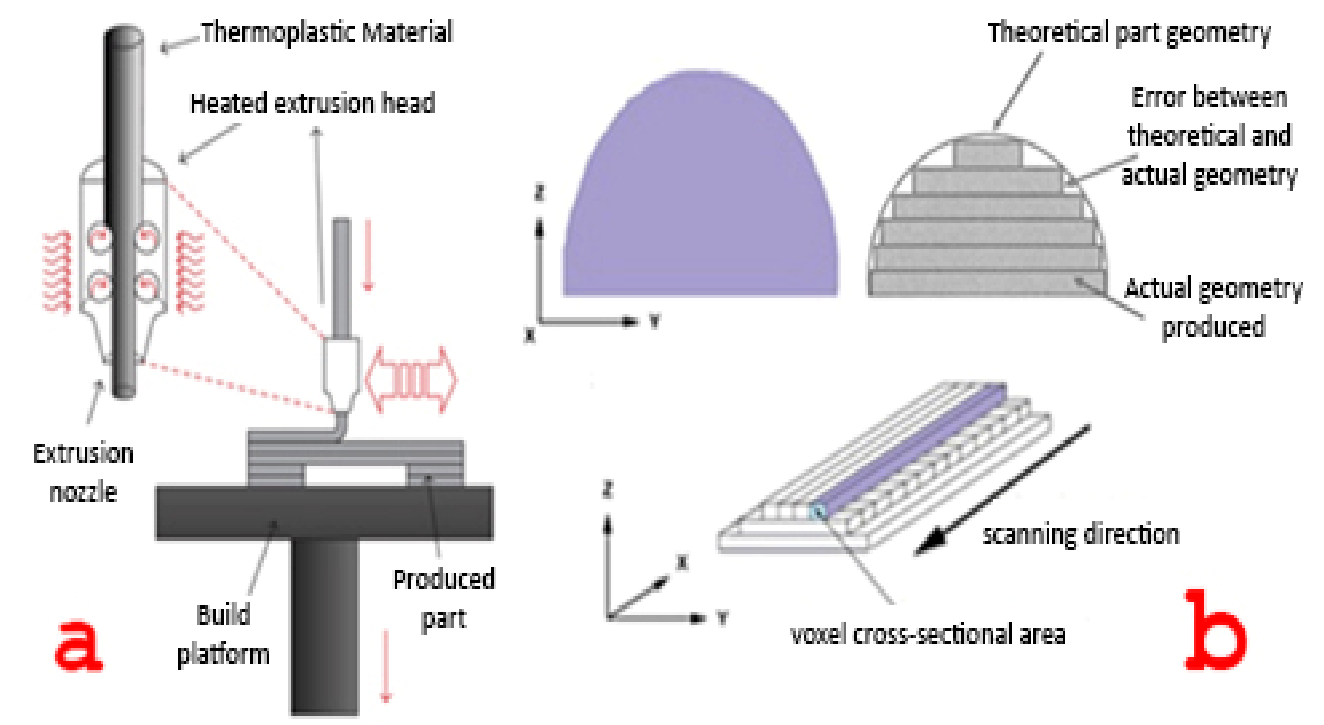

Fig. 2 FDM method (a) [13], layer scanning direction (b) [14], and stair stepping effect in AM (b) [7]. 
Table 1 Comparison of some 3D printers [15].

\begin{tabular}{|c|c|c|c|c|c|}
\hline Printer & Volume & Resolution & Speed & Material & Price \\
\hline $\begin{array}{l}\text { RepRap } \\
\text { Mendel }\end{array}$ & $\begin{array}{c}200 \times 200 \times 110 \\
(\mathrm{~mm})\end{array}$ & $\begin{array}{l}.1 \mathrm{~mm} \\
(\mathrm{dpi})\end{array}$ & $\begin{array}{c}150 \\
(\mathrm{~mm} / \mathrm{s})\end{array}$ & $\begin{array}{l}3 \mathrm{~mm} \\
\text { PLA }\end{array}$ & $\$ 830$ \\
\hline $\begin{array}{l}\text { MakerBot } \\
\text { Replicator }\end{array}$ & $\begin{array}{c}225 \times 145 \times 150 \\
(\mathrm{~mm})\end{array}$ & $\begin{array}{l}.2 \mathrm{~mm} \\
(\mathrm{dpi})\end{array}$ & $\begin{array}{c}45 \\
(\mathrm{~mm} / \mathrm{s})\end{array}$ & $\begin{array}{c}1.75 \mathrm{~mm} \\
\mathrm{ABS}\end{array}$ & $\$ 1750$ \\
\hline Ultimaker & $\begin{array}{c}210 \times 210 \times 220 \\
(\mathrm{~mm})\end{array}$ & $\begin{array}{l}.04 \mathrm{~mm} \\
(\mathrm{dpi})\end{array}$ & $\begin{array}{c}300 \\
(\mathrm{~mm} / \mathrm{s}) \\
\end{array}$ & $\begin{array}{l}3 \mathrm{~mm} \\
\text { PLA }\end{array}$ & $\$ 1570$ \\
\hline
\end{tabular}

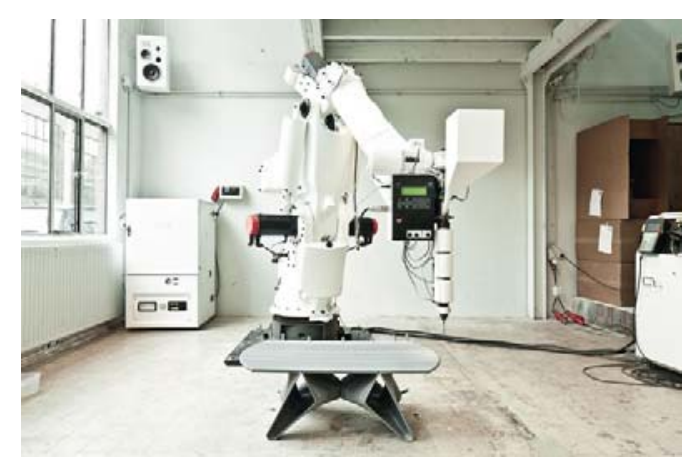

Fig. 3 Furoc 3D printers robotic arms [18].



(a)

(b)

Fig. 4 Layer thickness and surface roughness: (a) is $0.3 \mathrm{~mm}$ and $(\mathrm{b})$ is $0.15 \mathrm{~mm}$ [15].

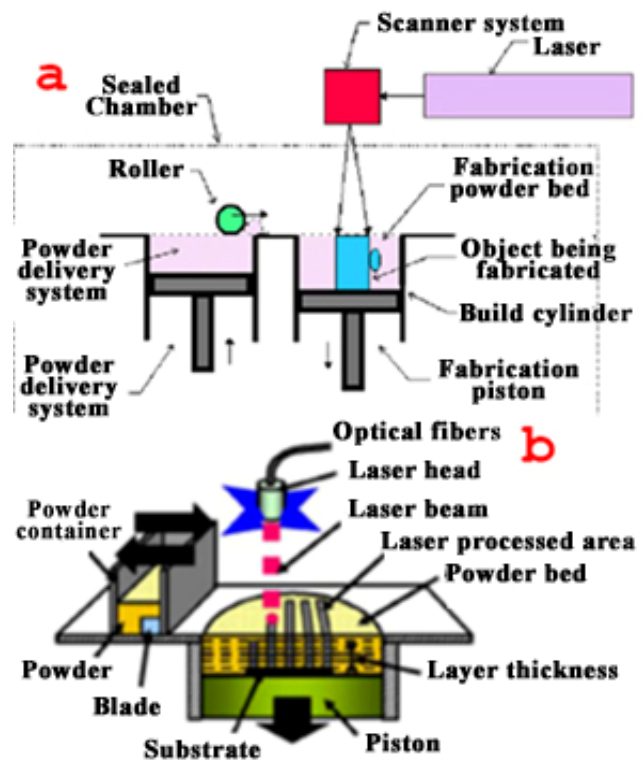

Fig. 5 Illustrations of (a) the SLS and (b) SLM [6].
SLM is a powder based method as shown in Fig. 5 b. It fuses the metal powders together with the energy in the form of high power laser beam. Lightweight parts for aerospace industry can be produced with this method.

SLS is similar to SLM process and there are two different powder beds, one is for powder supply and the other one is for forming the layers as shown in Fig. 5a. There is a laser source to select and sinter or melt the material powder as seen in the figure. After each layer formed production bed goes down by movement of the fabrication piston. At the end of production, powder must be cleaned by the help of vacuum system or else to take the product out. There is no need for the support parts to produce end goods by using metal and polymer powders with this method. But laser beam generates high temperatures and because of this products must be allowed for cooling to prevent any formal deformation.

Lamination is one of the methods for manufacturing furniture-look parts due to used material. It can use foils such as paper (new or recycled), plastic foam, ceramic or metal powder impregnated materials. Layers are laminated to each other by hot pressing cylinder with the laser beam. But system configuration changes if paper is being used. Fig. 6a shows configuration of lamination method and Fig. $6 \mathrm{~b}$ shows paper lamination technology.

The methods mentioned up to now use solid and powder or granular materials. But, Photopolymerisation or Stereolithography (SLA) uses photo-curable liquid plastic to form the model by beam of UV light. Liquid plastic called photopolymer and beam provided by UV laser or similar sources cures this liquid material. There is only fabrication bed or tank that photocurable resin filled in SLA in comparison with SLS as seen in Fig. 7. Building platform is driven down by elevator after each layer deposition of the part. Photocurable resin must be discharged to take out part when the model is finished. 


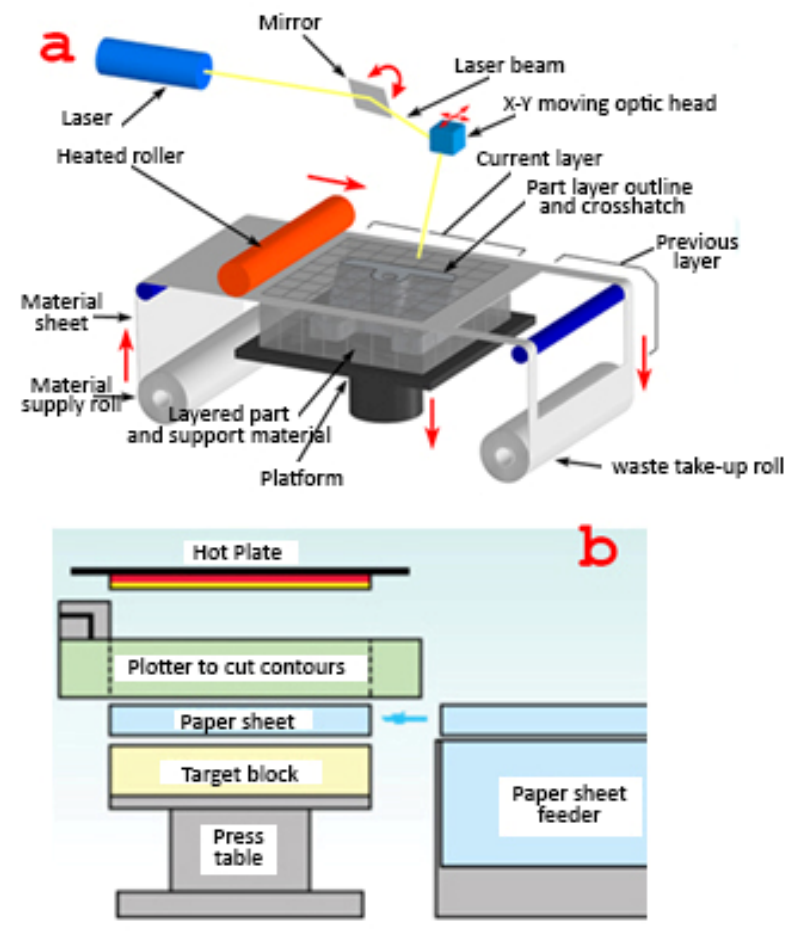

Fig. 6 (a) Laminated object manufacturing [12, 21] and (b) paper lamination technology [22].

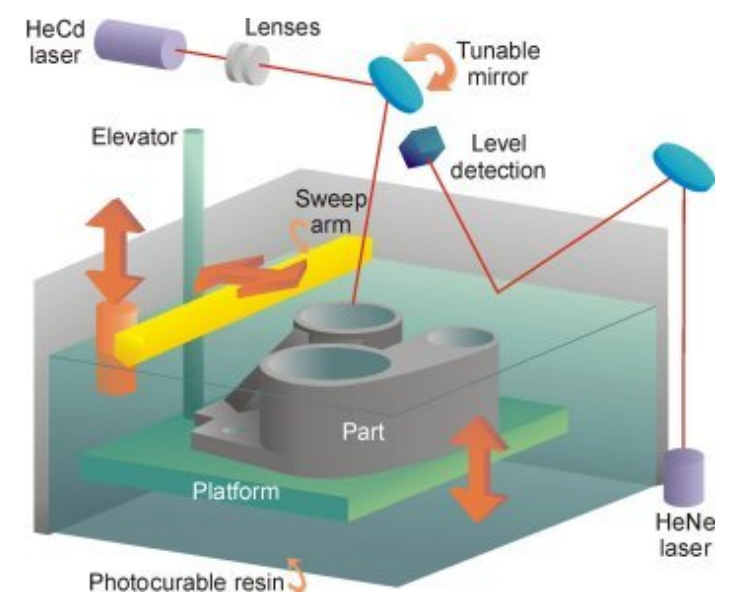

Fig. 7 Illustration of SLA method [23].

\section{Materials and Methods}

Nine different 3D printed furniture case studies have been reviewed for this study to find out how AM could be used for furniture production. These case studies were: Janne Kyttanen's Trabecula bench, Monarch stools and Sofa So Good, furnished chair, Lilian van Daal's 3D printed soft seat, Joris Laarman's puzzle chair, Clemens Weisshaar and Reed Kram's Multithread Escritoire table, Laywood-D3 wood based
3D printing filament and Minale-Maeda's 3D printed wood connectors. These applications were reviewed in terms of production method, assembly, material and design.

\section{Best Practice Examples in the Field of Furniture Products Made by AM}

Trabecula, one of the largest rapid-manufactured furniture in the world, is a near two meter long bench which is printed by using SLS method and glass filled polyamide material [24]. Powdered polyamide particles (thermo-plastic material) are sintered by laser energy to solidify sliced layers into the model. After sintering process that takes a day and a half, model must be cooled about 12 to 15 hours [24]. 3D CAD model is sliced into 6,000 cross sections and each section or layer has $1 / 12 \mathrm{~mm}$ thickness [24]. It has almost US $\$ 9,000$ price tag [25]. Bench has seven legs and a lace like surface and its design looks like Monarch stools as seen in Fig. 7. Because of this design, it is very light-weight but also has great strong structure which takes biomimetic cues from the bird bones [24]. Trabecula bench's production volume is limited to 10 units and color is available in graphite black and stone white [25]. As seen in Fig. 8, bench consisted of three pieces (build envelope of sintering machine is not suitable for final products) and then parts are assembled each other from interlocking pin joints, like dowel joint in carpentry, with cyanacrolate glue [24].

As Trabecula bench, butterfly patterned and lattice structured Monarch stools, seen in Fig. 9, were printed out from glass reinforced polyamide by SLS method. Each stool could be printed one piece and without a glue unlike the trabecular due to dimension $(36.5 \times 36$ $\times 37$ to $68 \mathrm{~cm}, \mathrm{H} \times \mathrm{W} \times \mathrm{L}$ ) and stacks each other. Price tag for nest of five is $£ 9,466$. They look like as a delicate accessory but they are expressively strong enough to seat as aforementioned Trabecula bench due to design and material properties.

Upholstery is one of the main activities in furniture production and provides an aesthetic look and comfort. 


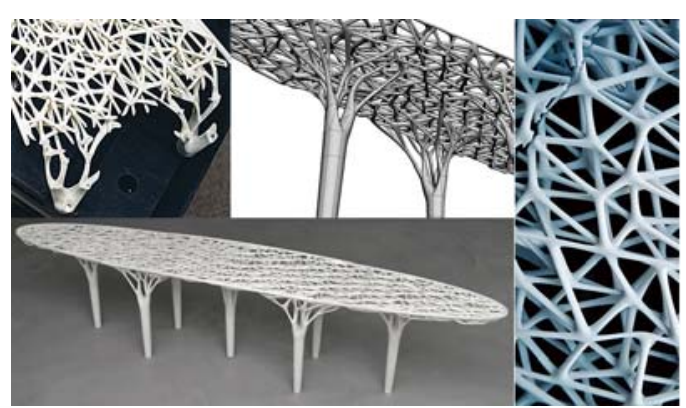

Fig. 8 Laser sintered Trabecula bench [24, 25].

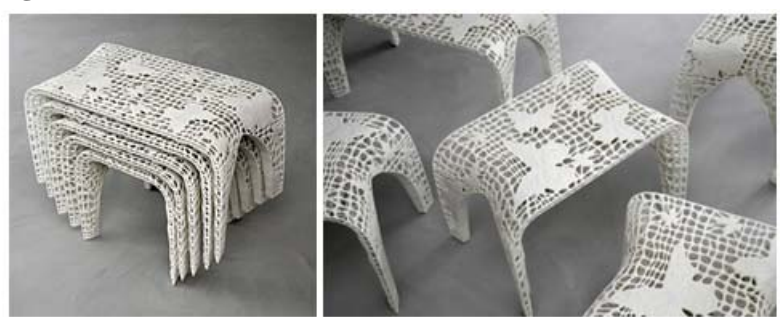

Fig. 9 Monarch stools [4].

Furnished chair, seen in Fig. 10, is manufactured in two steps. One is AM for wood like part manufacturing and other one is conventional process for furnishing. But, at first sight this chair looks like normal furniture due to its texture, grains, color and etc. that any other wood furniture would have. Beside this, design of this chair also allows the possibility to store some of stuffs such as book, magazine or else on to shelf like space. According to $4 \mathrm{AXYZ}$ firm, this could be achieved by their production technique which is different from layer-by-layer extruded 3D printing methods. In this technique, manufacturing process can be divided into two main steps: cutting small pieces of solid wood uniformly and combining these pieces to form layers by using a special binding process.

According to 4 AXYZ, $\$ 1.5$ million must be paid to own this 3D machine to print real-like furniture [27]. But, high labor cost could be minimized by using their trade secret machine or method and consumer has the flexibility to get customizable furniture in an affordable way within days of order. Also working with organic fibrous material can be achieved with this method for real look-like furniture manufacturing.

Traditional couches or upholstered furniture consist lots of different parts such as wood, leather, fabric, foam, plastic or else. Also these materials would be produced in different factories and then assembled. Each material has different properties and to recycle these materials is very difficult. First of all, parts must be separated from each other. But in AM, end goods can be produced in a few steps at the same facility by using just one material such as plastic. This provides easy recycling process at the end of products life cycle. 3D printed plastic chair, soft seat, has no frame, padding and covers for upholstery works but it has not only flexible surfaces that act like foam but also a $\mathrm{rigid} / \mathrm{stiff}$ structure as seen in Fig. 11. It is printed from polyamide by using laser sintering method in size of 45 $\times 45 \times 45 \mathrm{~cm}^{3}$ [28].

Weight is one of the main parameters of the AM due to used material density. 3D models are generally designed in lattice, mesh or similar forms to reduce weight. 3D printed sofa "Sofa so good" is a good example for this matter as seen in Fig. 12. Its dimensions are $150 \times 75 \times 55 \mathrm{~cm}^{3}$ and can hold up to $100 \mathrm{kgs}$ while it weighs only $2.5 \mathrm{kgs}$. It is strong due to its complex mesh design that was inspired by and mimicked of spiderweb and silkworms cocoons.

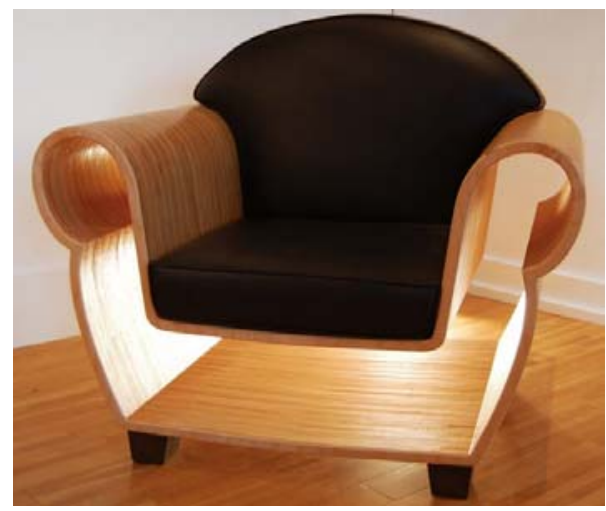

Fig. 10 Upholstered 3D printed chair [26].

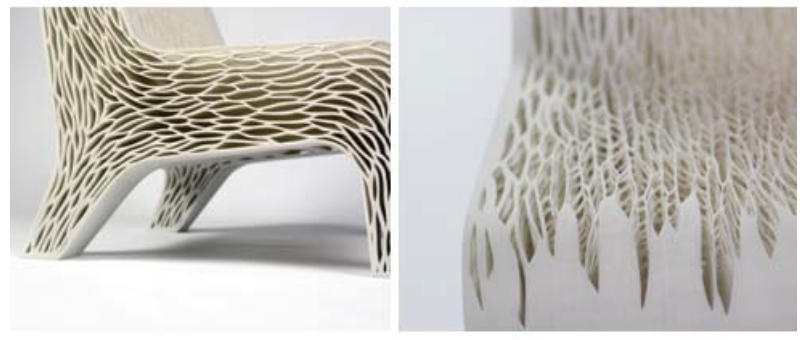

Fig. 11 3D printed soft seat [28]. 


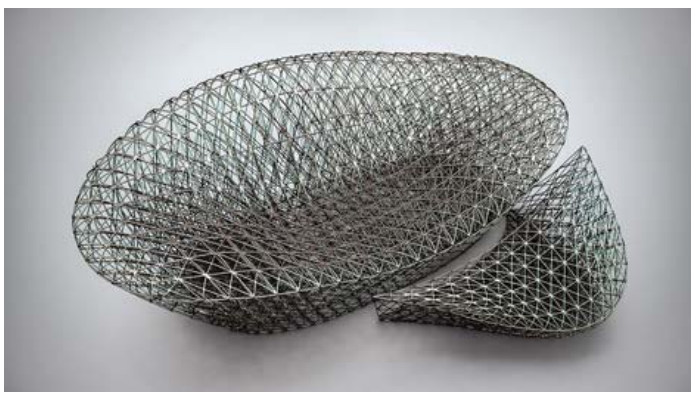

Fig. 12 Sofa so good [29].

This one-piece sofa was built by using Stereolithography (SLA) method and photo-reactive resins were cured with UV laser source [29]. Sofa consisted of 6,000 layers and each layer had $0.0099 \mathrm{~cm}$ thickness. It has copper and chrome plated finish and fabricated using only 2.5 liters of material [30].

Desktop printers are generally accepted as hobby type or home-use printers for small items. This means if you own such a printer you will probably use it to print small accessories instead of furniture. And according to Prindle [31] “3D printers aren't a common household appliance yet, but even if they were, making a full-sized piece of furniture typically requires you to print a boatload of small pieces and snap them together to create something bigger, which isn't very convenient". But actually you can have a 3D printed chair with a consumer type desktop printer as seen in Fig. 13. A puzzle blocks series, simple designed and made from white and black color PLA, were printed out by FDM method to be assembled into a chair. A proper and strong adhesive must be used to assemble the pieces together and provide stiff structure. Legs of this chair are wooden instead of 3D printed but connectors were printed from the same material as seen in Fig. 13.

Software is one of the main constituents of AM from design phase to calculations. 3D printed Multithread Escritoire table, seen in Fig. 14, is an obvious example to show how important the software is. Each joint of this table has different color illustrations obtained by use of finite element calculations on custom software. Calculations indicated the strains on these branch-like joints and that is why it has a special design. SLM

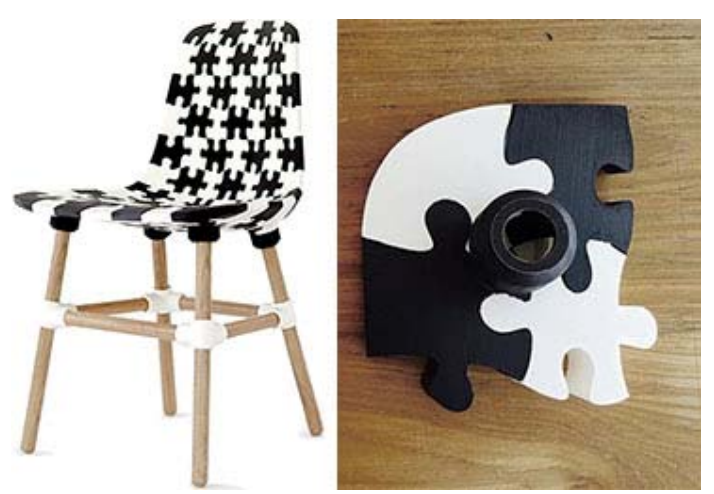

Fig. 13 Puzzle chair printed by desktop printer [32].

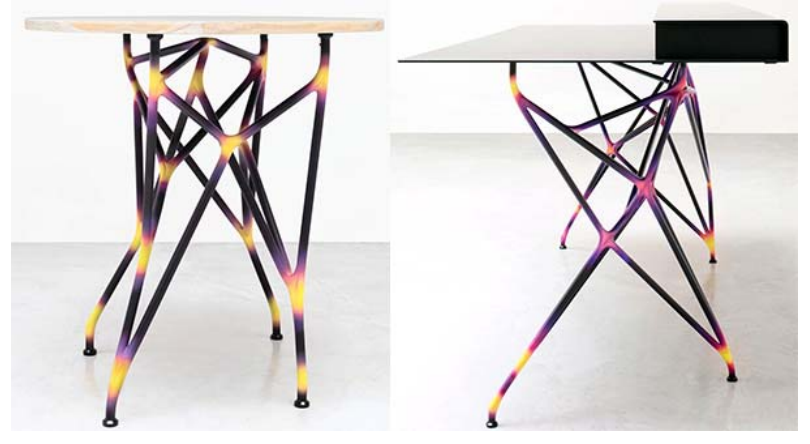

Fig. 14 Multithread Escritoire table [33].

method was used to print this table. This table is consisted of $3 \mathrm{D}$ printed aluminum joints, high tensile strength steel tube and powder coated aluminum shelf surface (right side) or Macedonian onyx tabletop. Price of this table was $€ 45.000$ excluding VAT [4].

Wood based filaments can be used to form layers in solid base FDM method. Wood-polymer composite Laywood-D3 is an example of this filament. This filament consists of $40 \%$ recycled wood and unharmful binding polymers [34]. It is a heat sensitive material and looks like cardboard or MDF as seen in left side of the Fig. 15. Heat sensitive material changes its color by temperature level inside of the extrusion nozzle. After the production it can be sanded and then painted for surface modification. According to Flaherty [34], its painting performance is better than PLA or ABS. Apart from this filament, as seen in the right side of Fig. 15, very fine powder of wood chips, flour or saw-dusts can be used to form MDF like surface, sandy, brown, granular and rough look, by laser sintering method even if this method is suitable especially for metal powder. But, laser sources generate high temperatures 




Fig. 15 Accessory that has a MDF like surface [34], 3D printed mask, wood flour (saw-dust) and UF binder [37].

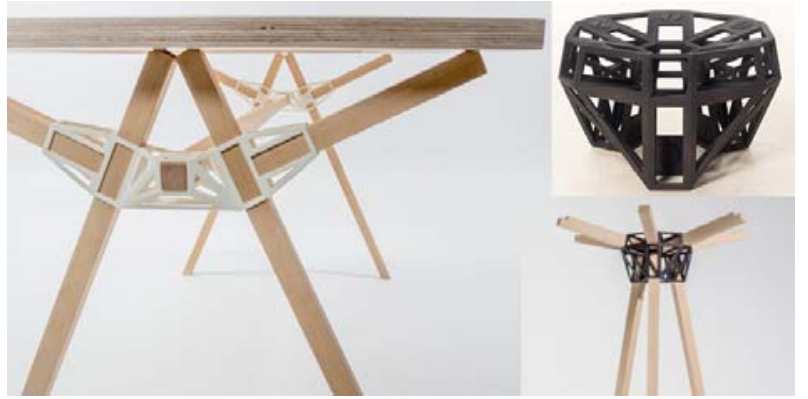

Fig. 16 3D printed furniture connectors [38].

and this can degrade wood material. Because of this, temperature of the sintered wood dust or chips must be in reasonable range. According to Henke and Treml [35] in 3D processes, large scale solids can be printed by using sawdust, wooden chips and etc. as bulk material with gypsum, cellulose, sodium silicate and cement as binder. This also means that contribution can be made for sustainable consumption and production. But, mechanical properties, dimensional accuracy and surface quality of the components which were printed with these wood-based composites must be evaluated as Wahab et al. [36] did.

Connectors are essential to assembly fixed or moving parts of furniture. AM manufacturing gives an opportunity to print personalized or downloaded connectors to fix furniture at home. Also their dimensions can be altered to fit personalized furniture components. But, essential parts such as surface table need to be shipped. These connectors would make joinery skills unnecessary in some cases due to easy use. Connectors, seen in Fig. 16, are made from plastic by FDM method. They can be easily printed by desktop $3 \mathrm{D}$ printers and this allows the possibility to assembly preordered components such as simple wood with connector you printed [38].

\section{Conclusions}

There are material limitations in AM including physical, economic (cost of material and process), and aesthetic (surface quality, color, transparency, texture and etc.) manner. Also mechanical properties should be analyzed before marketing the products. But, lots of these materials are more sustainable due to derivation from natural things such as plants. Wood based or wood derived materials become more of an issue because of their naturalness. Wood or wood based materials are the main inputs of furniture industry. As mentioned before, usability of recycled or indigenous materials like wood in furniture production by $\mathrm{AM}$ is important for balancing sustainable production and consumption ratio. This is why there is almost no material wastage in AM. But, as it could be understood from the reviews, AM is a promising method to produce unique consumer products but still expensive and not accessible.

AM lets users to manufacture consumer products in a few steps even if they have complex geometries. But, using the conventional manufacturing processes to fulfill these issues could be impossible in some cases. AM or alias Rapid Manufacturing is relatively slower than batch/serial production. This is the one of the main issue that is needed to be developed. But, when customization comes into prominence, AM provides design flexibility and so each piece of furniture could be printed distinctly. Also open-source of designs allows users to develop any of projects together such as "the puzzle chair" as seen in Fig. 14.

Finally, AM can be assumed as the future of modern manufacturing system and localization of the manufacturing. It can be said that furniture manufacturing by AM is relatively new. Non-industrial use of the AM in furniture production can be stated as one of the latest innovative development. And, it is clear that design phase of processes is more important than the others. So, it can be said that craftsmanship and other traditional activities would be affected negatively in the future by its potential if everything 
starts and ends between designer and printer.

\section{References}

[1] Gibson, I., Rosen, D. W., and Stucker, B. 2010. Additive Manufacturing Technologies. New York: Springer.

[2] Winnan, C. D. 2013. "3D Printers-The Next Technology Goldrush.” Online: Create Space.

[3] Berger, R. 2014. "Additive Manufacturing: A Game Changer for the Manufacturing Industry." http://www.rolandberger.com/media/pdf/Roland_Berger_ Additive_Manufacturing 20131129.pdf.

[4] Andres, T. 2014. "How 3D Printing Has Led to a Revolution in Furniture Design." http://www.ft.com/intl/cms/s/0/666baa2e-de7e-11e2-b99 0-00144feab7de.html.

[5] Anonym. 2013. "3D Printing Scales Up." http://www.economist.com/news/technology-quarterly/21 584447-digital-manufacturing-there-lot-hype-around-3dprinting-it-fast.

[6] Santos, E. C., Shiomi, M., Osakada, K., and Laoui, T. 2006. "Rapid Manufacturing of Metal Components by Laser Forming." International Journal of Machine Tools and Manufacture 46:1459-68.

[7] Majewski, C. 2011. "Applications of Evolutionary Computing to Additive Manufacturing." In Evolutionary Computing in Advanced Manufacturing, edited by Tiwari, M., and Harding, J. A. New Jersey: John Wiley and Sons.

[8] Hopkinson, N., Hauge, R. J. M. and Dickens, P. M. 2006. Rapid Manufacturing: An Industrial Revolution for the Digital Age. West Sussex: John Wiley and Sons.

[9] Buswell, R. A, Soar, R. C., Gibb, A. G. F, and Thorpe, A. 2007. "Freeform Construction: Mega-Scale Rapid Manufacturing for Construction." Automation in Construction 16: 224-31.

[10] Koç, M., and Ozel, T. 2011. Micro-manufacturing: Design and Manufacturing of Micro-products. Hoboken: John Wiley and Sons.

[11] Dudek, P. 2013. "FDM 3D Printing Technology in Manufacturing Composite Elements." Archives of Metallurgy and Materials 58 (4): 1415-8.

[12] Celik, I., Karakoc, F., Cakir, M. C., and Duysak, A. 2013. "Hızlı Prototipleme Teknolojileri ve Uygulama Alanları" Dumlupinar University Graduate School of Science and Technology Journal 31: 53-70.

[13] Tsouknidas, A. 2011. "Friction Induced Wear of Rapid Prototyping Generated Materials: A Review." Advances in Tribology 2011: 1-7.

[14] http://illumin.usc.edu/assets/media/1017/Figure2_Rapid_ prototyping_slicing.jpg .

[15] Evans, B. 2012. Practical 3D Printers: The Science and Art of 3D Printing. NewYork: Apress.
[16] Krassenstein, E. 2014. "French Company, Drawn, Is Now 3D Printing Entire Furniture Pieces. And They Are Amazing." http://3dprint.com/6853/drawn-3d-printed-furniture/.

[17] Dehue, R. 2014. "Dirk van der Kooij's 3D Printed furniture."

http://3dprinting.com/3dprinters/dirk-van-der-kooijs-3d-p rinted-furniture/.

[18] Anon. 2013. "Chubby Chairs by Dirk Van Der Kooij." http://www.despoke.com/2013/06/01/chubby-chairs-by-d irk-van-der-kooij/.

[19] Dogan, G. 2007. "Mikro ve Nano Hizlı Prototipleme." Master thesis, Yildiz Technic University Graduate School of Natural and Applied Sciences.

[20] Lanzetta, M., and Sachs, E. 2003. "Improved Surface Finish in 3D Printing Using Bimodal Powder Distribution." Rapid Prototyping Journal 9 (3): 157-66.

[21] Chua, C. K., Leong, K. F., and Lim, C. S. 2010. Rapid Prototyping: Principles and Applications. 3rd edition. Singapore: World Scientific Publishing.

[22] Boboulos, M. A. 2010. CAD-CAM and Rapid Prototyping Application Evaluation. Tellirude: Ventus Publishing.

[23] Millius, D. L. 2001. "Research: Chemical Energy Conversion and Power Generation at the Microelectromechanical Systems (MEMS) Scale." http://www.princeton.edu/ cml/html/research/mems.html.

[24] Gardiner. V. 2008. “The Trabecula Bench.” Dwell Small Wonders 8 (4): 107-10.

[25] http://cubify.com/store/design/FnDZNFyiw5pB.

[26] Luimstra, J. 2014. "Wondering What 3D Printed Wood Looks Like?" http://3dprinting.com/news/future-talk-3d-printing-woode n-furniture/.

[27] Anon. 2014. "4 AXYZ Seeks \$1m via Indiegogo for 3D Printing Real Wood Furniture.” http://www.3ders.org/articles/20140424-4-axyz-seeks-ind iegogo-for-3d-printing-real-wood-furniture.html.

[28] Sher, D. 2014. "Biomimicry Inspired Soft Seat Makes Comfortable Seating More Natural." http://3dprintingindustry.com/2014/08/13/biomimicry-ins pired-soft-seat-makes-comfortable-seating-natural/.

[29] Anon. 2015. "Janne Kyttanen Builds 3D-Printed Sofa from a Minimal Mesh." http://www.dezeen.com/2015/06/02/janne-kyttanen-3d-pr inted-sofa-so-good-minimal-mesh-spider-web-cocoons/.

[30] Wheeler, A. 2015. "Inspired By Nature-Meet Janne Kyttanen \& His 3D Printed Sofa So Good." http://3dprintingindustry.com/2015/05/31/inspired-by-nat ure-meet-janne-kyttanen-his-3d-printed-sofa-so-good/.

[31] Prindle, D. 2014. "3D-Printed 'Keystones' Open the Door to Cheap, Sturdy DIY Furniture." http://www.digitaltrends.com/home/keystone-connectors- 
make-furniture-with-a-single-3d-printed-piece/.

[32] http://www.bitsandparts.org/.

[33] http://www.kramweisshaar.com/projects/multithread.

[34] Flaherty, J. 2013. "3-D Printing Branches Out with New Wood-Based Filament." http://www.wired. com/design/2012/11/3d-printer-wood-filament/.

[35] Henke, K., and Treml, S. 2013. "Wood Based Bulk Material in 3D Printing Processes for Applications in Construction." Europen J. Wood Products 71: 139-41.

[36] Wahab, Md. S., Wagiman, A., and Ibrahim, M. 2013.
"Development of Wood-Based Composites Material for 3D Printing Process." Applied Mechanics and Materials 315: 987-91.

[37] Peels, J. 2013. "3D Printing in Wood Flour." http://i.materialise.com/blog/entry/3d-printing-in-wood-fl our.

[38] Anon. 2014. "Anyone Can Make DIY Furniture with These 3D-Printed Wood Connectors." http://www.3ders. org/articles/20140421-anyone-can-make-diy-furniture-wi th-these-3d-printed-wood-connectors.html. 